\title{
The Role of Transposable Element or Jumping Genes in Cancers
}

\section{Abolfazl Movafagh}

Department of Medical Genetics, cancer Research Center, Shohada Hospital, School of Medicine, Shahid Beheshti University of Medical Science, Tehran, Iran.

\begin{abstract}
Genomic, proteomic, transcriptomic, and epigenomic analyses of human tumors indicate that there are thousands of anomalies within each cancer genome compared to matched normal tissue. Based on these analyses it is evident that there are many undiscovered genetic drivers of cancer. Performing an unbiased forward genetic screen in human provides the tools to generate tumors and analyze their genetic composition, while reducing the background of passenger mutations. The transposon system is one such method that can be inserted throughout the genome by the transposable element. A transposable element or jumping genes (TE or transposon) is a DNA sequence that can change its position within a genome, sometimes creating or reversing mutations and altering the cell's genome size. Transposable elements make up a large fraction of the genome and are responsible for much of the mass of DNA in a eukaryotic cell. There are at least two classes of TEs: Class I TEs or retrotransposons generally function via reverse transcription, while Class II TEs or DNA transposons encode the protein transposase, which they require for insertion and excision, and some of these TEs also encode other proteins. The most common transposable element in humans is the Alu sequence. It is approximately 300 bases long and can be found between 300,000 and one million times in the human genome. Alu alone is estimated to make up 15-17\% of the human genome. Transposon s are mutagens and their movements are often the causes of genetic disease. They can damage the genome of their host cell in different ways. A transposon or a retrotransposon that inserts itself into a functional gene will most likely disable that gene causing cancers. After a DNA transposon leaves a gene, the resulting gap will probably not repaired correctly.
\end{abstract}

Keywords: Transposons- element- human- cancer- jumping gene

Asian Pac J Cancer Biol, 1 (4), 75-76

Diseases often caused by TEs include predisposition to cancer. Since its inception the conditional transposon mutagenesis system has been applied to many cancer types, identifying hundreds of candidate cancer genes, generating new cancer models, and providing insights into the genes and mechanisms of cancer progression. The development of transposons elements and its use for cancer gene discovery has been a boon for cancer functional genomics studies. It has led to the discovery of new and specific cancer drivers critical to human tumor development or maintenance such as field of transposons elements , and others. [1-11]
Submission Date: 08/15/2016 Acceptance Date: 11/25/2016

\section{References}

1. Bucher E, Reinders J, Mirouze M. Epigenetic control of transposon transcription and mobility in Arabidopsis. Current opinion in plant biology. 2012;15(5):503-10.

2. Janik CL, Starr TK. Identification of Sleeping Beauty transposon insertions in solid tumors using linkermediated PCR. Journal of visualized experiments : JoVE. 2013(72):e50156.

3. Klawitter S, Fuchs NV, Upton KR, Munoz-Lopez M, Shukla $\mathrm{R}$, Wang J, et al. Reprogramming triggers endogenous L1 and Alu retrotransposition in human induced pluripotent stem cells. Nature communications. 2016;7:10286.

4. Macia A, Widmann TJ, Heras SR, Ayllon V, Sanchez L, Benkaddour-Boumzaouad M, et al. Engineered LINE-1

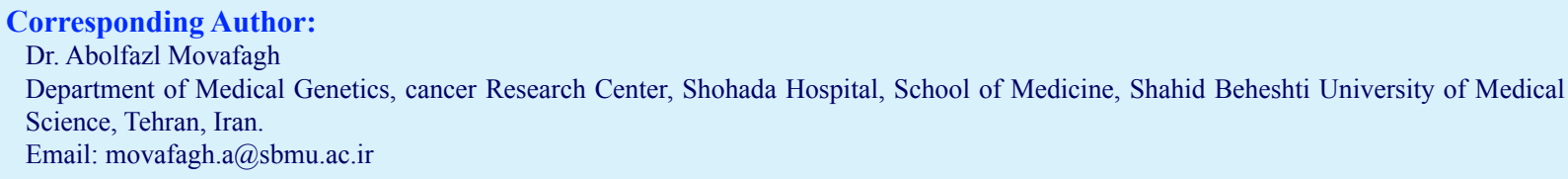


retrotransposition in nondividing human neurons. Genome research. 2017;27(3):335-48.

5. Movafagh A MF, Fadaie S, AzarGashb E Persistent unstable chromosomal aberrations in lymphocytes of radiotherapy workers after 1st mitotic division in Tehran, Iran. . Pakistan Journal of Medical Sciences (2007).23;:254-8. .

6. Munoz-Lopez M, Vilar-Astasio R, Tristan-Ramos P, LopezRuiz C, Garcia-Perez JL. Study of Transposable Elements and Their Genomic Impact. Methods in molecular biology (Clifton, NJ). 2016;1400:1-19.

7. Munoz-Lopez M, Medina PP, Garcia-Perez JL. Wiping DNA methylation: Wip1 regulates genomic fluidity on cancer. Cancer cell. 2013;24(4):405-7.

8. Munoz-Lopez M, Garcia-Canadas M, Macia A, Morell S, Garcia-Perez JL. Analysis of LINE-1 expression in human pluripotent cells. Methods in molecular biology (Clifton, NJ). 2012;873:113-25.

9. Munoz-Lopez M, Macia A, Garcia-Canadas M, Badge RM, Garcia-Perez JL. An epi [c] genetic battle: LINE-1 retrotransposons and intragenomic conflict in humans. Mobile genetic elements. 2011;1(2):122-7.

10. Pray LA. "Transposons: The jumping genes".(2008). . 204. p.

11. Seifi-Alan M, Shamsi R, Ghafouri-Fard S, Mirfakhraie R, Zare-Abdollahi D, Movafagh A, et al. Expression analysis of two cancer-testis genes, FBXO39 and TDRD4, in breast cancer tissues and cell lines. Asian Pacific journal of cancer prevention : APJCP. 2014;14(11):6625-9.

\section{(ब) $(8$}

This work is licensed under a Creative Commons AttributionNon Commercial 4.0 International License. 